University of Nebraska - Lincoln

DigitalCommons@University of Nebraska - Lincoln

2012

\title{
Utility of Improvised Video-Camera Collars for Collecting Contact Data From White-Tailed Deer: Possibilities in Disease Transmission Studies
}

\author{
Michael J. Lavelle \\ National Wildlife Research Center, michael.j.lavelle@aphis.usda.gov \\ Scott E. Hygnstrom \\ University of Nebraska-Lincoln, shygnstrom1@unl.edu \\ Aaron M. Hildreth \\ University of Nebraska-Lincoln, hildreta@gmail.com \\ Tyler A. Campbell \\ National Wildlife Research Center, tyler.a.campbell@aphis.usda.gov \\ David B. Long \\ National Wildlife Research Center, david.b.long@aphis.usda.gov
}

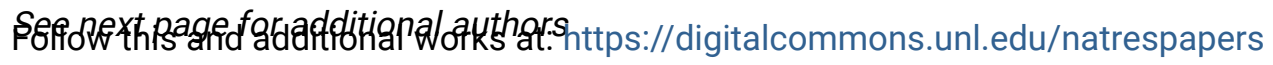

Part of the Natural Resources and Conservation Commons, Natural Resources Management and Policy Commons, and the Other Environmental Sciences Commons

Lavelle, Michael J.; Hygnstrom, Scott E.; Hildreth, Aaron M.; Campbell, Tyler A.; Long, David B.; Hewitt, David G.; Beringer, Jeff; and VerCauteren, K. C., "Utility of Improvised Video-Camera Collars for Collecting Contact Data From White-Tailed Deer: Possibilities in Disease Transmission Studies" (2012). Papers in Natural Resources. 372.

https://digitalcommons.unl.edu/natrespapers/372

This Article is brought to you for free and open access by the Natural Resources, School of at DigitalCommons@University of Nebraska - Lincoln. It has been accepted for inclusion in Papers in Natural Resources by an authorized administrator of DigitalCommons@University of Nebraska - Lincoln. 


\section{Authors}

Michael J. Lavelle, Scott E. Hygnstrom, Aaron M. Hildreth, Tyler A. Campbell, David B. Long, David G.

Hewitt, Jeff Beringer, and K. C. VerCauteren 


\title{
Utility of Improvised Video-Camera Collars for Collecting Contact Data From White-Tailed Deer: Possibilities in Disease Transmission Studies
}

\author{
MICHAEL J. LAVELLE, United States Department of Agriculture, Animal and Plant Health Inspection Service, Wildlife Services, \\ National Wildlife Research Center, Fort Collins, CO 80521-2154, USA \\ SCOTT E. HYGNSTROM, University of Nebraska, School of Natural Resources, Lincoln, NE 68583-0974, USA \\ AARON M. HILDRETH, University of Nebraska, School of Natural Resources, Lincoln, NE 68583-0974, USA \\ TYLER A. CAMPBELL, United States Department of Agriculture, Animal and Plant Health Inspection Service, Wildlife Services, \\ National Wildife Research Center, Florida Field Station, Gainesville, FL 32641, USA \\ DAVID B. LONG, United States Department of Agriculture, Animal and Plant Health Inspection Service, Wildlife Services, \\ National Wildife Research Center, Florida Field Station, Gainesville, FL 32641, USA \\ DAVID G. HEWITT, Caesar Kleberg Wildlife Research Institute, Texas AEM University-Kingsville, Kingsville, TX 78363-8202, USA \\ JEFF BERINGER, Missouri Department of Conservation, Conservation Research Center, Columbia, MO 65201, USA \\ KURT C. VERCAUTEREN, ${ }^{1}$ United States Department of Agriculture, Animal and Plant Health Inspection Service, Wildlife Services, \\ National Wildlife Research Center, Fort Collins, CO 80521-2154, USA
}

\begin{abstract}
Rapidly evolving electronic technology enables wildlife researchers to collect previously unobtainable data. To explore possibilities of using deer-borne cameras (DBCs) to collect behavioral data from an animal's point of view, we constructed DBCs and deployed them on 26 adult male whitetailed deer (Odocoileus virginianus) within a closed population (405-ha fenced area) in southern Texas just prior to the breeding season during autumn 2010. Our DBCs consisted of global positioning system collars with attached motion-activated trail cameras. We obtained 21,474 video clips from 17 functional DBCs over a period of 14 days. Individual-based data are invaluable in disease and population modeling; therefore, we confirmed the identify of 37 individual deer in field of view of DBCs based on ear tags, collar numbers, and antler characteristics (e.g., point counts, relative mass, tine length). Additionally, we recorded 85 contacts, including 36 with identifiable deer, involving breeding $(n=1)$, sparring $(n=63)$, grooming $(n=5)$, and muzzle contact $(n=16)$. Our results demonstrate the value of using DBCs to record direct contacts and associated behaviors and even to enable estimation of contact rates, thus improving the understanding of the potential for transmission of disease pathogens. Published 2012. This article is a U.S. Government work and is in the public domain in the USA.
\end{abstract}

KEY WORDS behavior, camera, disease transmission, observation, Odocoileus virginianus, Texas, video, white-tailed deer.

White-tailed deer (Odocoileus virginianus; hereafter, deer) behavior has been studied largely through direct observation (e.g., Michael 1968, Hirth 1977, Ozoga and Verme 1985). The quality of behavioral data collected through direct observations is affected by observability bias (Altmann 1952, Beringer et al. 2004). Emerging management needs regarding the mechanisms of intra- and interspecies transmission of pathogens has increased the demand for more efficient means of collecting behavioral data to detect contact and thus estimate potential transmission rates $(\mathrm{McC}$ allum et al.

Received: 13 September 2011; Accepted: 25 June 2012

Published: 30 November 2012

Additional supporting information may be found in the online version of this article.

${ }^{1}$ E-mail: kurt.c.vercauteren@aphis.usda.gov
2001, Schauber and Woolf 2003, Schauber et al. 2007). The current mathematical models used to estimate effects of disease on populations are based on assumptions of contact rates (Schauber and Woolf 2003). Contemporary telemetry techniques have provided limited inference regarding contact rates (Schauber et al. 2007); novel tools such as camera collars may facilitate a more accurate and complete characterization, resulting in better estimates.

Very high frequency (VHF) radio telemetry and, more recently, global positioning system (GPS) technologies are commonly used to determine locations, home ranges, and movements of deer, and to quantify deer interactions (e.g., Doncaster 1990, Minta 1992, Beringer et al. 2004). Collars that incorporate GPS minimize field effort and improve accuracy of locations (Bowman et al. 2000, D'Eon et al. 2002); these locations can reveal spatial and temporal overlap 
(joint space use) among individuals that may infer potential for transmission of pathogens (Schauber et al. 2007). These potential "interactions," however, lack accuracy and visual confirmation needed to determine spatio-temporal proximity and specificity of interactions (Rosenberry et al. 2001, Naylor and Kie 2004, Schauber et al. 2007). Recently developed proximity loggers go one step further in documenting more fine-scale interactions; though they still lack in ability to characterize true physical contact or interactions with potential for transmission of disease agents (Perkins et al. 2009). Though these technologies for monitoring wildlife movements are widely used, they are inadequate for characterizing actual behavior (Beringer et al. 2004).

Direct observations can reveal behavior and contact rates, but they are labor-intensive and provide limited inference regarding contact rates because of observability bias (Creech 2011) To overcome observability issues, researchers have developed and employed automated cameras (e.g., Gysel and Davis 1956, Winkler and Adams 1968, Cutler and Swann 1999, Swann et al. 2004). However, a primary drawback of using automated cameras for collecting behavioral data is that they are stationary, and thus capture limited data from a fixed position.

More recently, researchers have developed and evaluated transmission-based, data-collecting video-camera systems and animal-borne video and environmental data-collection systems to obtain behavioral data including, but not limited to, white-tailed deer (Beringer et al. 2004, Cooke et al. 2004, Moll et al. 2007, Moll 2008). Transmission-based, datacollecting video-camera systems require video to be transmitted from deer-borne cameras (DBCs) to a receiving station. A maximum transmission range of $500 \mathrm{~m}$ limited the practicality of these systems (Beringer et al. 2004). Incorporating store-on-board capabilities increased their utility for use on free-ranging animals, though longevity of monitoring was still battery-limited (Moll 2008).

Novel camera collars and proximity loggers may prove invaluable tools for collecting interaction data, and thus providing new insights into disease transmission dynamics by enabling collection of more complete data (Silbernagel 2010). Additionally, camera collars may begin to provide a more comprehensive view of reality and contact rates therein by documenting activity by all individuals within the field of view and not just those that are outfitted with electronics (Habib et al. 2011). We devised a suitable DBC prototype and conducted a mass deployment with the objective of evaluating its potential for collecting video depicting behaviors that could have implications in disease transmission and begin to provide estimates of contact rates.

\section{STUDY AREA}

We conducted our evaluation on private land near Zapata within Zapata County, Texas, USA $\left(26^{\circ} 54^{\prime} \mathrm{N}, 99^{\circ} 16^{\prime} \mathrm{W}\right)$ in the South Texas Plains region. The climate of the region was generally mild with a growing season of 340-360 days; average annual temperatures ranged from $19^{\circ} \mathrm{C}$ to $23^{\circ} \mathrm{C}$, and annual rainfall averaged $43 \mathrm{~cm}$ (Taylor et al. 1999). Deer were captured within a 405 -ha property enclosed by a $2.5-\mathrm{m}$ woven-wire fence and managed for recreational purposes. The property consisted of xeric uplands and lacustrine areas bordering a large reservoir. Overstory vegetation consisted primarily of shrubs and small trees, including honey mesquite (Prosopis glandulosa), acacia (Acacia spp.), and tamarisk (Tamarix spp.). The herbaceous layer was dominated by buffelgrass (Cenchrus ciliaris) with an abundance of prickly pear cactus (Opuntia engelmannii).

\section{METHODS}

We constructed the $\mathrm{DBC}$ s from production-model Telonics GPS collars (Fig. 1; TGW-4500 GPS/SOB; Telonics, Inc., Mesa, AZ) outfitted with commercially available motionactivated trail cameras (Fig. 1; Model 119435C, Trophy $\mathrm{Cam}^{\text {TM}}$; Bushnell ${ }^{\circledR}$ Outdoor Products, Overland Park, $\mathrm{KS})$. We affixed cameras to the GPS housing with coldweld compound $\left(\mathrm{J}-\mathrm{B}^{\circledR}\right.$ Weld Company, Sulphur Springs, TX) and perforated metal strapping (high-tensile heavy-duty strapping; Independent Metal Strap, Roslyn, NY) positioned facing forward approximately $25 \mathrm{~cm}$ below the junction of the bottom jaw and the neck (Fig. 1) and perpendicular to the ground.

The cameras were powered with long-life and lightweight lithium AA batteries (Ultimate Lithium Batteries; Energizer ${ }^{\circledR}$, Saint Louis, MO). Cameras were activated by an internal passive infrared motion sensor that could be programmed at low, normal (i.e., medium), and high settings depending on desired sensitivity and ambient temperature. The passive infrared motion sensor had a range of $13.7 \mathrm{~m}$ with a trigger speed of $<1 \mathrm{~s}$ (manufacturer-stated specification). The video obtained was in full color during daylight and black and white at night, with the aid of 32 infrared light-emitting diodes. Resolution was adjustable from $320 \times 240 / 30$ frames $/ \mathrm{s}$ to $720 \times 480 / 30$ frames $/ \mathrm{s}$, with a $50^{\circ}$ field of view. We programmed cameras to collect a 30-s high-resolution video clip $(720 \times 480$ pixels/frame at 30 frames/s) when motion was detected at the normal sen-

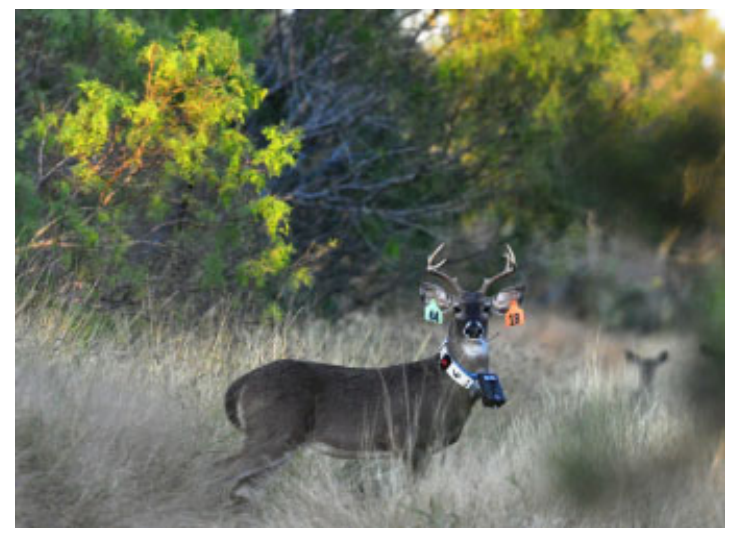

Figure 1. Animal-borne cameras incorporating motion-activated videocapture technologies on white-tailed deer (Odocoileus virginianus) evaluated during autumn 2010 near Zapata, Texas, USA. Collars used also included a Very High Frequency (VHF) transmitter, Global Position System, proximity logger, and programmable release. 
sitivity setting, with a time lag of 5 min before the DBC could be triggered again. Manufacturer-stated maximum allowable 16-gigabyte (GB) secure digital (SD) cards (Lexar Secure Digital High Capacity; Lexar Media, Inc., Fremont, CA) were used for data storage.

The DBCs also had proximity loggers with VHF beacons (E2C 181C; Sirtrack ${ }^{\circledR}$, Havelock North, New Zealand) and programmable collar-release mechanisms (CR-2a; Telonics, Inc.). To maximize potential for collection of interaction data, we extended the duration of deployment based on estimated battery life and storage capacity (Table 1) while attempting to minimize potential for damage or loss; thus, we programmed collar releases to activate 14 days after deployment. As constructed, the total cost for each DBC in this study was US\$2,837.

With the goal of capturing pre-breeding-season interactions between males, we deployed DBCs on 26 mature male deer for 14 days in autumn 2010, just prior to the beginning of breeding season for deer in the region (Hellickson 2002), which peaks regionally on approximately 21 December (Illige 1951, Ruthven et al. 1995). The DBCs weighed $1.5 \mathrm{~kg}$, or approximately $2 \%$ of body mass, based on regional weights of adult male deer (Hellickson 2002). An earlier assessment on animal stress related to bulk of DBCs demonstrated no difference in fecal glucocorticoid metabolite levels between deer outfitted with collars and those without (Moll et al. 2009). Deer were captured with net guns from a helicopter [as described by Webb et al. (2007)], blindfolded and hobbled, transported to a processing location $(<1 \mathrm{~km}$ away) where they were fitted with DBCs and large livestock eartags with unique numeric codes (Allflex ${ }^{\circledR}$, Dallas Fort Worth Airport, TX), and released. We used eartags with bold codes printed on front and rear to facilitate identification of individuals on video. Helicopter capture enabled deployment of all DBCs in $<4 \mathrm{hr}$, which allowed us to collect immediate interactions (i.e., contacts) among our study animals. All procedures were approved by the Institutional Animal Care and Use Committee of the U.S. Department of Agriculture-Animal and Plant Health Inspection Service-Wildlife Services-National Wildlife Research Center (USDA-APHIS-WS-NWRC, QA-1591).

We retrieved DBCs using VHF telemetry receivers and hand-held antennae the day the collars dropped from deer.

Table 1. Estimated minimum potential duration of function for deer-borne cameras (DBCs; based on storage capacity of $14.9 \mathrm{~GB}$ ) set to available videoquality options on white-tailed deer (Odocoileus virginianus), evaluated during autumn 2010 near Zapata, Texas, USA.

\begin{tabular}{lcc}
\hline $\begin{array}{l}\text { Camera video size setting } \\
\text { (pixels) }\end{array}$ & $\begin{array}{c}\text { Mean file size } \\
(\text { KB) })^{\mathbf{a}}\end{array}$ & $\begin{array}{c}\text { Days of } \\
\text { function }^{\mathbf{b}}\end{array}$ \\
\hline $320 \times 240$ & 2,283 & 24.9 \\
$640 \times 480$ & 9,058 & 6.3 \\
$720 \times 480$ & 10,165 & 5.6 \\
\hline
\end{tabular}

${ }^{a}$ Calculated from 3 clips in full-color format, 3.4\% larger than nighttime digital video clips.

${ }^{\mathrm{b}}$ Estimated from max. no. of clips/day (i.e., triggering every $5 \mathrm{~min}$ $30 \mathrm{~s}=262$ clips).
Upon collection of DBCs, we transferred data from SD cards to a computer hard drive. We reviewed video clips on desktop computers and noted the following: time of day, habitat type occupied, plant species consumed, behaviors exhibited, nature of interactions (including occurrence and characterization of physical contact with other deer), and identifying characteristics of other deer encountered. We used contact counts/total video time (no. clips $\times 0.5 \mathrm{~min} / 60 \mathrm{~min}$ ) $/ \mathrm{DBC}$ to estimate contact rates (no./hr) and provide means with standard errors. To determine overall durability and potential for use of similar trail cameras in DBCs, we recorded and present status and overall condition of retrieved DBCs, number of video segments recorded per DBC, and duration of DBC function.

\section{RESULTS}

We captured, collared, and released 26 deer between $0800 \mathrm{hr}$ and $1200 \mathrm{hr}$ on 29 November 2010. One animal died during capture and another died within 2 days after being outfitted with a DBC; however, we did not determine cause of death. We retrieved all collars on the day of the programmed dropoff date. Status of DBCs was as follows: 17 held data; 16 were still functional; 4 had moisture-damaged cards; 2 had SD cards missing; 2 were separated from their collars and were not retrieved; and 1 had only the battery compartment intact. Damage to DBCs that allowed water and debris to enter the housing included cracked covers over motion sensors (7 of 22), light-emitting diodes (5 of 22), and camera lens ( 1 of 22). Five DBCs were subject to brief power loss during deployment, and thus did not maintain correct time and date. From the DBCs that maintained the correct date and time $(n=13)$, we recorded a mean of $631.6 \mathrm{~min}$ $(\mathrm{SD}=249.3)$ of video over $3-13.3$ days $(\bar{x}=7.7$ days, $\mathrm{SD}=3.1$ ) of $\mathrm{DBC}$ function. Nine $\mathrm{DBCs}$ captured $>1,550$ video clips, totaling $>14.9 \mathrm{~GB}$ each (apparent usable capacity), and did so in an average of 7.2 days (range $=5.7-$ 9.0 days, $\mathrm{SD}=1.1)$. One $\mathrm{DBC}$ reached maximum data storage capacity in 5.7 days, which suggests that card capacity was a limiting factor. Conversely, $3 \mathrm{DBC}$ did not reach capacity until day 8 or 9 of the study, while another only collected 985 clips over the entire study.

We recorded 85 contacts, including 36 with identifiable deer. Overall, from ear tags, collar numbers, and antler characteristics (Fig. 2), we were able to identify 37 other marked deer that appeared in the field of view of DBCs. We also recorded 63 occasions where males made antler contact with one another, 16 muzzle contacts, 5 grooming or licking instances, and 1 breeding event. For identifiable deer, mean contact rates were 0.35 contacts $/ \mathrm{hr}$. $(\mathrm{SE}=0.09$ ) and $\geq 5$ individuals were contacted by 2 DBC-equipped deer.

We obtained video footage from the vantage point of the deer wearing DBCs to include the habitat they used. Habitats where deer bedded or fed were identifiable (Fig. 3), although nighttime video from bedded animals recorded only immediately adjacent vegetation, which accentuates the need for knowledge of the vegetation species associated with particular habitats of the study area. 


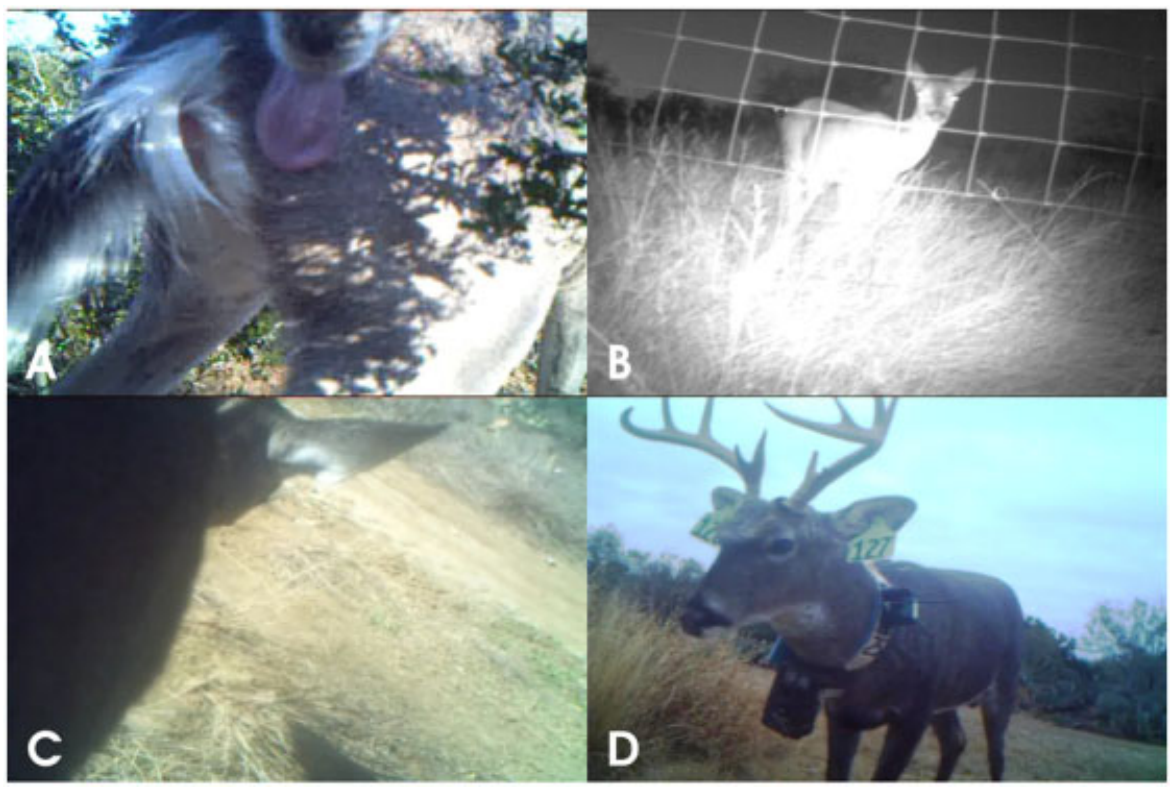

Figure 2. Intra-specific interactions captured with animal-borne cameras on white-tailed deer (Odocoileus virginianus) during autumn 2010 near Zapata, Texas, USA. Interactions identifiable from digital video images included (A) licking the posterior of another deer, (B) interacting with an unmarked female through a fence, (C) mounting an unmarked female, and (D) close interaction with another collared individual.

Species of vegetation consumed, such as prickly pear cactus, blackbrush acacia ( $A$. rigidula), and buffelgrass also were identifiable (Fig. 4).

\section{DISCUSSION}

Fine-scale spatial data, such as those pertaining to inter- and intraspecies encounters that may pose a risk of pathogen transmission, are difficult to obtain using traditional monitoring technology. The DBCs enabled us to document interactions among targeted conspecifics. Although camera-equipped collars were not commercially available at the time of our study, integration of existing products enabled us to collect similar data. Recently, production-model, collar-mounted video cameras have become available (Lotek video-camera collar, Lotek Wireless Inc., Newmarket, Ontario, CA), and their use in collecting difficult-to-obtain data has been demonstrated (Thompson et al. 2012). At a cost approaching US $\$ 3,000 /$ unit, however, their use may be cost-prohibitive for many wildlife behavior applications. Additional bulk of GPS and proximity loggers, as reported in this study, would likely be unnecessary for most studies, which emphasizes that components should be selected to

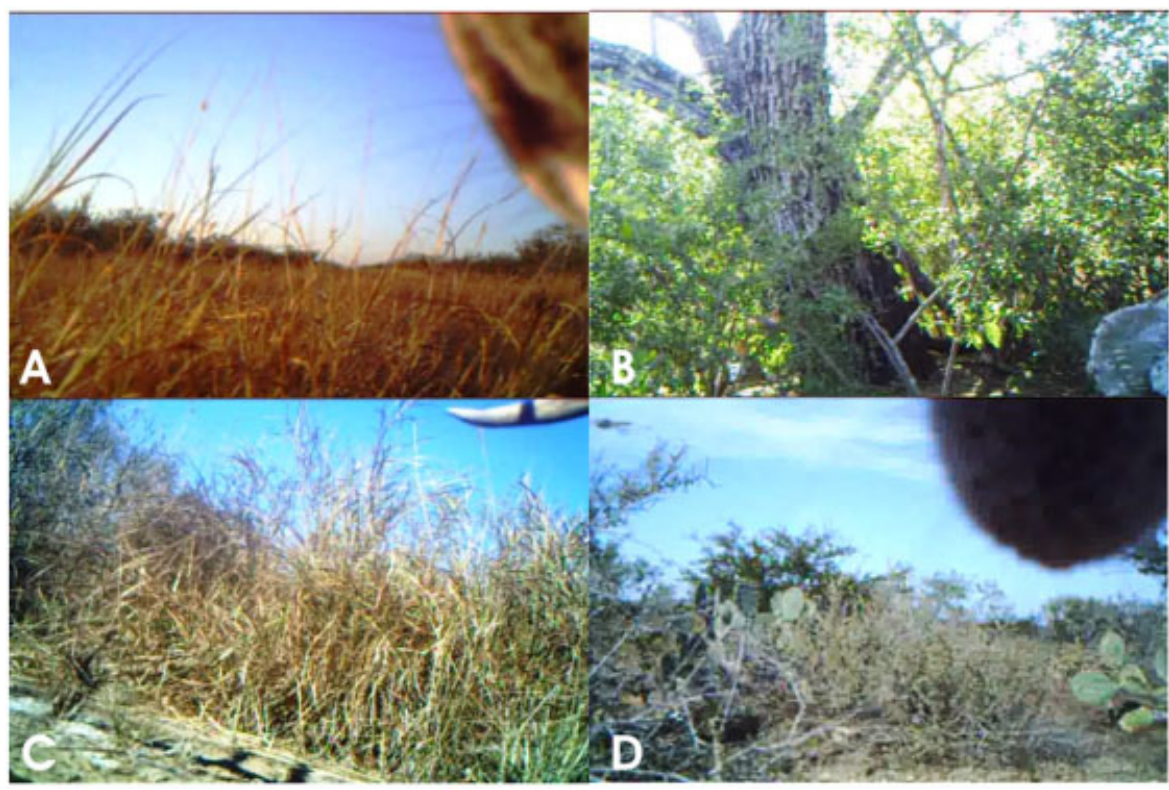

Figure 3. Vegetative habitat-type data captured with animal-borne cameras on white-tailed deer (Odocoileus virginianus) during autumn 2010 near Zapata, Texas, USA. Cover types identifiable from digital video images include (A) grassland, (B) mesquite-acacia, (C) riparian, and (D) shrubland. 


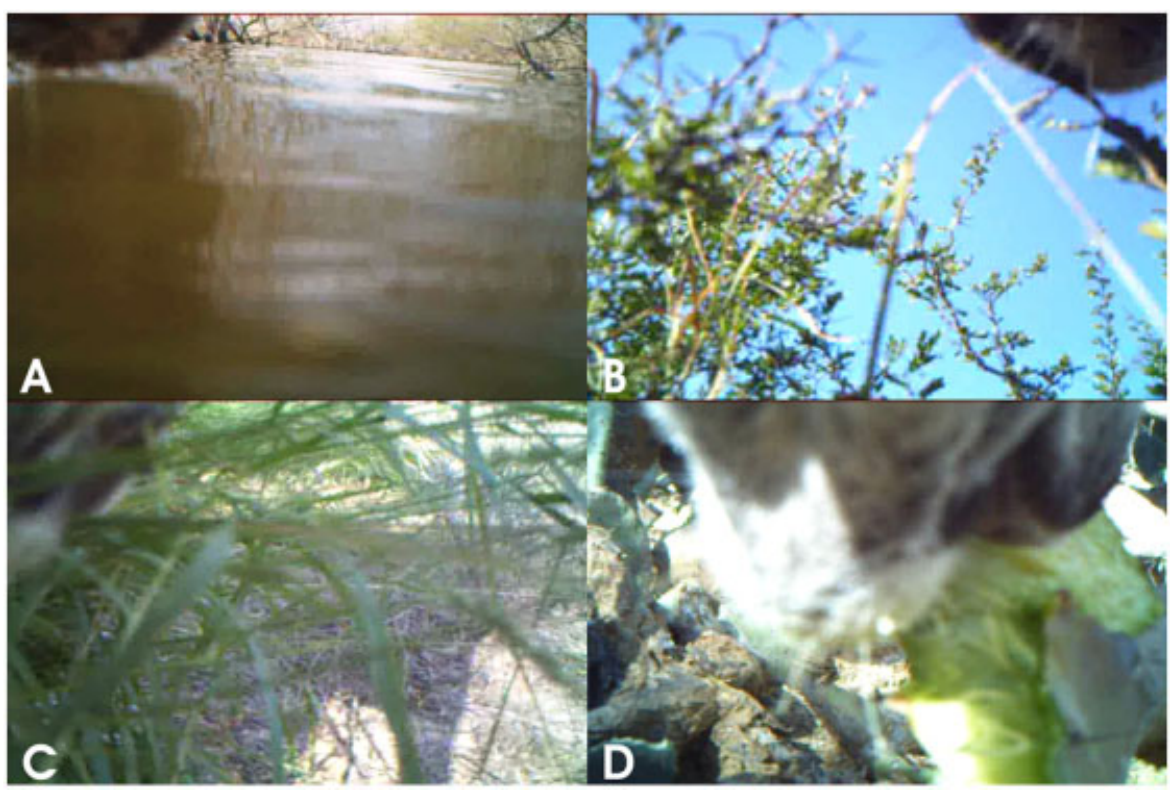

Figure 4. Consumption data captured with animal-borne cameras on white-tailed deer (Odocoileus virginianus) during autumn 2010 near Zapata, TX, USA. Behaviors identifiable from digital video images include (A) drinking from lake, (B) consumption of blackbrush acacia (Acacia rigidula) leaves, (C) consumption of buffelgrass (Cenchrus ciliaris), and (D) consumption of prickly pear cactus (Opuntia engelmannii).

meet objectives of the particular study being considered. Fortunately, more simplistic combinations of a mounting harness with improvised degradable release (i.e., surgical tubing), simple VHF radiotransmitter (to facilitate retrieval), and motion-activated trail camera (such as we used) may be more economically feasible, with costs $<$ US $\$ 500$ (Table 2).

The trail cameras we used were not designed to be mounted on animals; thus, overall durability and potential for damage in this application was anticipated. Specific vulnerabilities included damage to camera lenses, light-emitting diode arrays, and motion sensors. To mitigate the loss of DBCs, we recommend attaching a tether cable to both collar and camera to improve retrieval rates. Video suggested that cameras were susceptible to damage by barbed-wire fences as deer crossed over or through the fences. Issues with power loss from loose batteries appeared to have been addressed in more recent camera models, and these may be remedied in older models through insertion of packing material (e.g., closed-cell foam) between batteries and the camera housing.

When we conducted this study, data storage capacity was limited to 16-GB SD cards (14.9-GB actual usable capacity); however, 32-GB cards are now compatible with new cameras from Bushnell (i.e., Model 119436C, Trophy Cam). Data storage capacity is also directly related to video resolution, and our cameras were programmed to record video at high resolution.

Future research using DBCs should consider video resolution when outlining objectives and project duration (Table 1). Studies focusing on habitat or food selection may require higher resolution settings that may not be necessary for studies with other objectives; the latter case would allow for longer duration before reaching memory storage capacity and battery life expiration. At the normal motion-sensitivity setting, DBCs triggered routinely even while DBC-outfitted animals were bedded; this suggests that sensitivity selection may enable users to target specific behaviors. For example, selecting the low-sensitivity setting may minimize the amount of triggering from movement of the collared animal and limit capture to movement of other animals within the field of view of the camera.

By mounting cameras slightly below the bottom jaw, we were able to observe the jaw of the deer and thereby confirm activities such as consumption and class of vegetation, at times to the level of species (Fig. 4). Researchers have

Table 2. Costs associated with assembling deer-borne cameras, as evaluated and at a reduced cost, for capturing behavioral data from white-tailed deer (Odocoileus virginianus) in autumn 2010 near Zapata, Texas, USA.

\begin{tabular}{|c|c|c|}
\hline Component & As evaluated (US\$) & Inexpensive construction $^{a}$ \\
\hline Collar & Telonics TGW-4500 GPS-\$1,900 & VHF-\$255+ \\
\hline Camera & Bushnell $^{\mathbb{Q}}$ Trophy Cam ${ }^{\mathrm{TM}}-\$ 170$ & Camera- $\$ 130+$ \\
\hline Release mechanism & Telonics CR-2a-\$300 & Latex tubing- $\$ 1$ \\
\hline SD memory card & Lexar Secure Digital -16 GB- $\$ 30$ & $32 \mathrm{~GB}-\$ 33+$ \\
\hline AA lithium batteries (8) & Energizer $^{\mathrm{TM}}$ Ultimate Lithium- $\$ 12$ & $\$ 12$ \\
\hline Proximity logger & Sirtrack E2C $181 \mathrm{C}-\$ 425$ & Optional \\
\hline Total & $\$ 2,837$ & $\$ 431$ \\
\hline
\end{tabular}

\footnotetext{
${ }^{\text {a }}$ Inexpensive construction costs based on prices from telemetry collar manufacturers and Amazon.com.
} 
observed hand-reared ungulates feeding in natural habitats to characterize consumption, and they have described details that would likely be overlooked if observations were from afar (Wallmo et al. 1973, Hobbs et al. 1981). Details such as consumption of fallen leaves or single kernels of corn from the ground were evident in our videos, though they would likely be indistinguishable by observations from a distance.

Single images have been used previously to document behaviors, and these remain suitable for collecting data for limited purposes such as habitat-use indices (Beringer et al. 2004, Moll 2008). Benefits of capturing video rather than single images are that multiple frames prior to and after a particular image of interest enable observers to determine the actual behavior taking place (Marshall et al. 2007, Moll 2008; five representative videos available online). For example, a photograph of the jaw of a deer near an identifiable species of cactus, such as prickly pear, would not confirm consumption, but video of the deer taking a bite would do so (Fig. 4; Video 1). In addition, nature of interactions (Fig. 2) can be characterized from video, but would be challenging or impossible from single images. When considering level of activity, it is unlikely that observers could differentiate among animals moving, resting, or standing still by reviewing single images, whereas it is possible with video (Fig. 5; Video 2). Further, we were able to document habitat type occupied by deer when video was captured (Fig. 3). Traditional methods of determining habitat use from GPS locations within coarse habitat designations or GIS layers and without on-the-ground verification have potential to miss fine-scale differences that we were able to characterize with DBCs.

Collection of unbiased behavioral data is a challenge, especially when observing secretive or nocturnal animals (Moll 2008). We originally considered conducting visual observations to measure interactions between individuals, but recognized challenges associated with extensive labor requirements, potential observer bias, and variable constraints such as limited lighting and field of view. Our use of DBCs enabled us to efficiently capture video that documented contacts among individual deer (Video 3), and to calculate contact rates that could contribute to pathogen transmission, at any hour of the day (Fig. 2; Video 4). Although limitations such as cost, capture and handling requirements, and limited duration of deployment exist, the versatility of $\mathrm{DBC}$ s for research studies emphasizes their value as a unique new tool contributing to the field of wildlife research and justifies further development (Moll 2008). As technology continues to advance, especially relative to camera size and durability, digital storage capacity, and battery life, we predict rapid and substantial advances to animalborne cameras.

\section{MANAGEMENT IMPLICATIONS}

The DBC system could be used to address specific management-related questions, such as deer use of underpasses or livestock feed. Difficult-to-obtain details, such as food preference, response to human activity, and interaction with other species (including livestock) could also be documented with DBCs (Video 5). Costs and options associated with instrumenting deer with $\mathrm{DBC}$ s are directly related to duration of deployment and type of data required (i.e., length of video segments, still shots, fine-scale GPS locations, etc.). For example, questions that could be answered with camera deployment of short duration with no spatial emphasis, such as in this evaluation, would be a good application for lower cost assemblages, including degradable release mechanisms and inexpensive VHF transmitters. Conversely, deployments of longer duration and spatial emphasis would require more durable construction with larger capacity memory cards and GPS units, which would result in higher cost. As research

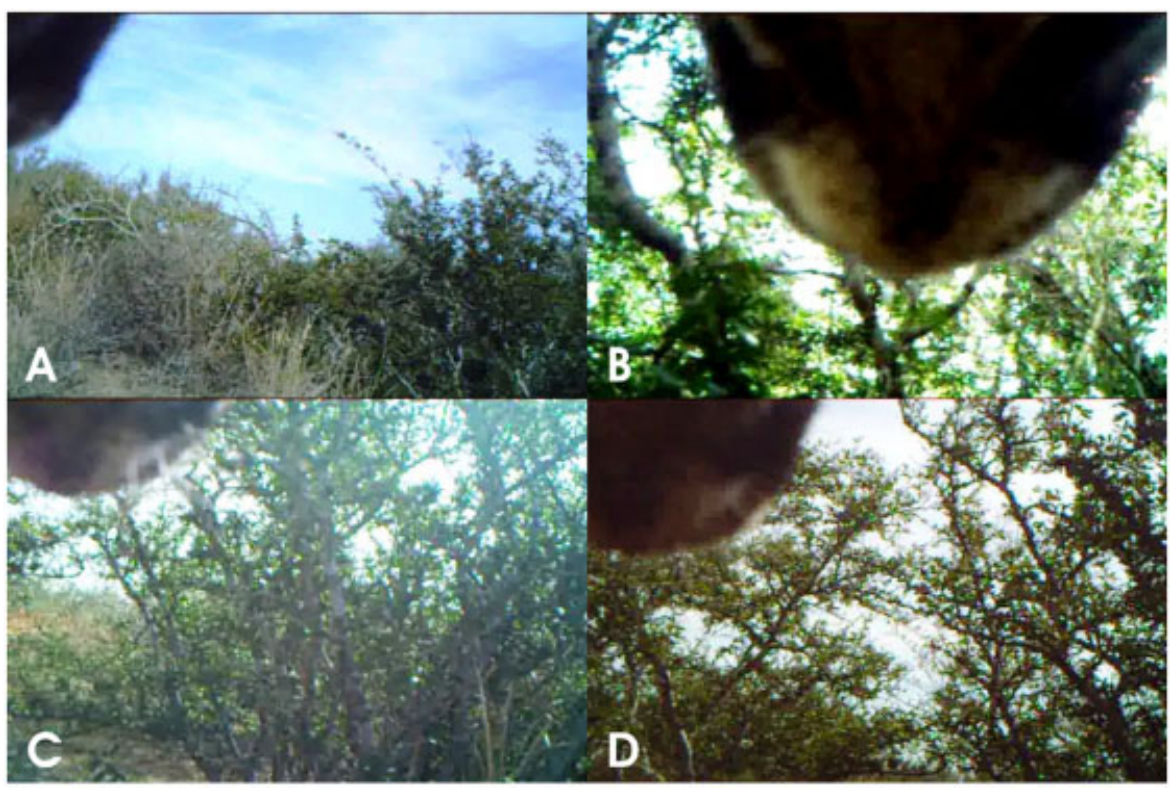

Figure 5. Activity data captured with animal-borne cameras on white-tailed deer (Odocoileus virginianus) during autumn 2010 near Zapata, Texas, USA. This image compilation demonstrates the difficulty in differentiating various behaviors from single images: (A) running, (B) bedded, (C) walking, and (D) standing still. 
needs arise, camera collars are a tool that should be considered because they can be constructed inexpensively and with minimal skills, and can enable researchers and managers to collect unbiased data from the point of view of the individual target animals.

\section{ACKNOWLEDGMENTS}

We thank G. Schuster, L. Soliz, C. Ellis, R. Pleszewski, C. Anderson, C. Minor, T. Ruby, J. Rhyan, M. McCollum, P. Nol, G. Clements, and USDA-APHIS-Veterinary Services for assisting with various aspects and responsibilities of the study. We also thank L. Hansen, R. Moll, J. Millspaugh, J. Sartwell, and R. Woeck for preparatory work leading up to this larger scale evaluation of DBCs on deer. We thank the Caesar Kleberg Wildlife Research Institute at Texas A\&M University-Kingsville and USDA-APHIS-WS-Texas for logistic support. We are grateful to the USDA-APHIS-WS-NWRC for financial support. Mention of companies or commercial products does not imply recommendation or endorsement by the USDA nor does omission imply criticism. Product names are mentioned solely to report factually on available equipment and to provide specific information.

\section{LITERATURE CITED}

Altmann, M. 1952. Social behavior of elk, Cervus canadensis nelsoni, in the Jackson Hole area of Wyoming. Behavior 4:116-143.

Beringer, J., J. J. Millspaugh, J. Sartwell, and R. Woeck. 2004. Real-time video recording of food selection by captive white-tailed deer. Wildlife Society Bulletin 32:648-654.

Bowman, J. L., C. O. Kochanny, S. Demarais, and B. D. Leopold. 2000. Evaluation of a GPS collar for white-tailed deer. Wildlife Society Bulletin 28:141-145.

Cooke, S. J., S. G. Hinch, M. Wikelski, R. D. Andrews, L. J. Kuchel, T. G. Wolcott, and P. J. Butler. 2004. Biotelemetry: a mechanistic approach to ecology. Trends in Ecology and Evolution 19:334-343.

Creech, T. G. 2011. Contact rates in ecology: using proximity loggers to explore disease transmission on Wyoming's elk feedgrounds. Thesis, Montana State University, Bozeman, USA.

Cutler, T. L., and D. E. Swann. 1999. Using remote photography in wildlife ecology: a review. Wildlife Society Bulletin 27:571-581.

D'Eon, R. G., R. Serrouya, G. Smith, and C. O. Kochanny. 2002. GPS radiotelemetry error and bias in mountainous terrain. Wildlife Society Bulletin 30:430-439.

Doncaster, C. P. 1990. Non-parametric estimates of interaction from radiotracking data. Journal of Theoretical Biology 143:431-443.

Gysel, L. W., and E. M. Davis. 1956. A simple automatic photographic unit for wildlife research. Journal of Wildlife Management 20:451-453.

Habib, T. J., E. H. Merrill, M. J. Pybus, and D. W. Coltman. 2011. Modelling landscape effects on density-contact rate relationships of deer in eastern Alberta: implications for chronic wasting disease. Ecological Modelling 222:2722-2732.

Hellickson, M. W. 2002. Age-specific physical characteristics, activity, and behavior patterns of male white-tailed deer in southern Texas. Dissertation, University of Georgia, Athens, USA.

Hirth, D. H. 1977. Social behavior of white-tailed deer in relation to habitat. Wildlife Monographs 53.

Hobbs, N. T., D. L. Baker, J. E. Ellis, and D. M. Swift. 1981. Composition and quality of elk winter diets in Colorado. Journal of Wildlife Management 45:156-171.
Illige, D. 1951. An analysis of the reproductive pattern of whitetail deer in South Texas. Journal of Mammalogy 32:411-421.

Marshall, G., M. Bakhtiari, M. Shepard, J. Tweedy, III, D. Rasch, K. Abernathy, B. Joliff, J. C. Carrier, and M. R. Heithaus. 2007. An advanced solid-state animal-borne video and environmental datalogging device ("Crittercam") for marine research. Marine Technology Society Journal 41:31-38.

McCallum, H., N. Barlow, and J. Hone. 2001. How should pathogen transmission be modeled? Trends in Ecology and Evolution 16:295-300.

Michael, E. D. 1968. Aggressive behavior of white-tailed deer. The Southwestern Naturalist 13:411-420.

Minta, S. C. 1992. Tests of spatial and temporal interaction among animals. Ecological Applications 2:178-188.

Moll, R. J. 2008. Development and evaluation of a terrestrial animal-borne video system for ecological research. Thesis, University of Missouri, Columbia, USA.

Moll, R. J., J. J. Millspaugh, J. Beringer, J. Sartwell, and Z. He. 2007. A new 'view' of ecology and conservation through animal-borne video systems. Trends in Ecology and Evolution 22:660-668.

Moll, R. J., J. J. Millspaugh, J. Beringer, J. Sartwell, R. J. Woods, and K. C. VerCauteren. 2009. Physiological stress response of captive white-tailed deer to video collars. Journal of Wildlife Management 73:609-614.

Naylor, L. M., and J. G. Kie. 2004. Monitoring activity of Rocky Mountain elk using recording accelerometers. Wildlife Society Bulletin 32:1108-1113.

Ozoga, J. J., and L. J. Verme. 1985. Comparative breeding behavior and performance of yearling vs. prime-age white-tailed bucks. Journal of Wildlife Management 49:364-372.

Perkins, S. E., F. Cagnacci, A. Stradiotto, D. Arnoldi, and P. J. Hudson. 2009. Comparison of social networks derived from ecological data: implications for inferring infectious disease dynamics. Journal of Animal Ecology 78:1015-1022.

Rosenberry, C. S., M. C. Conner, and R. A. Lancia. 2001. Behavior and dispersal of white-tailed deer during the breeding season. Canadian Journal of Zoology 79:171-174.

Ruthven, D. C., E. C. Hellgren, D. A. Draeger, R. E. Hall, M. W. Hellickson, and C. Y. DeYoung. 1995. Comparison of reproductive characteristics with nutritional indices and age in white-tailed deer in southern Texas. (Abstract). Proceedings of the Southeast Deer Study Group 18:28-29.

Schauber, E. M., D. J. Storm, and C. K. Nielsen. 2007. Effects of joint space use and group membership on contact rates among white-tailed deer. Journal of Wildlife Management 71:155-163.

Schauber, E. M., and A. Woolf. 2003. Chronic wasting disease in deer and elk: a critique of current models and their application. Wildlife Society Bulletin 31:610-616.

Silbernagel, E. 2010. Factors affecting movement patterns of mule deer (Odocoileus hemionus) in Southern Saskatchewan: implications for chronic wasting disease spread. Thesis, University of Saskatchewan, Saskatoon, Canada.

Swann, D. E., C. C. Haas, D. C. Dalton, and S. A. Wolf. 2004. Infraredtriggered cameras for detecting wildlife: an evaluation and review. Wildlife Society Bulletin 32:357-365.

Taylor, R. B., J. Rutledge, and J. G. Herrera. 1999. A field guide to common South Texas shrubs. Texas Parks and Wildlife, Austin, USA.

Thompson, I. D., M. Bakhtiari, A. R. Rodgers, J. A. Baker, J. M. Fryxell, and E. Iwachewski. 2012. Application of a high-resolution animal-borne remote video camera with global positioning for wildlife study: observations on the secret lives of woodland caribou. Wildlife Society Bulletin 36:365-370. http://onlinelibrary.wiley.com/doi/10.1002/wsb.130/pdf.

Wallmo, O. C., R. B. Gill, L. H. Carpenter, and D. W. Reichert. 1973. Accuracy of field estimates of deer food habits. Journal of Wildlife Management 37:556-562.

Webb, S. L., J. S. Lewis, D. G. Hewitt, M. W. Hellickson, and F. C. Bryant. 2007. Assessing the helicopter and net gun as a capture technique for white-tailed deer. Journal of Wildlife Management 72:310-314.

Winkler, W. G., and D. B. Adams. 1968. An automatic movie camera for wildlife photography. Journal of Wildlife Management 32:949-952.

Associate Editor: Messmer. 